Int. J. Electrochem. Sci., 15 (2020) 1893 - 1903

International Journal of

ELECTROCHEMICAL

SCIENCE

www.electrochemsci.org

\title{
Electrochemical and Computational Studies on the Corrosion Inhibition of Mild Steel by 1-Hexadecyl-3-methylimidazolium Bromide in $\mathrm{HCl}$ Medium
}

\author{
Jianhong Tan $^{1}$, Lei Guo ${ }^{2, *}$, Dan $W u^{1}$, Shanfei Wang ${ }^{1}$, Rongrong Yu ${ }^{2}$, Fan Zhang ${ }^{3}$, Savaş Kaya ${ }^{4}$ \\ ${ }^{1}$ School of Chemistry and Chemical Engineering, Yangtze Normal University, Chongqing 408100, \\ China \\ ${ }^{2}$ School of Material and Chemical Engieering, Tongren University, Tongren 554300, China \\ ${ }^{3}$ Division of Surface and Corrosion Science, Department of Chemistry, KTH Royal Institute of \\ Technology, Stockholm SE-10044, Sweden \\ ${ }^{4}$ Cumhuriyet University, Faculty of Science, Department of Chemistry, 58140, Sivas, Turkey \\ *E-mail: cqglei@163.com
}

doi: $10.20964 / 2020.03 .36$

Received: 30 October 2019 / Accepted: 29 December 2019 / Published: 10 February 2020

\begin{abstract}
An imidazolium-based ionic liquid, i.e., 1-Hexadecyl-3-methylimidazolium Bromide (HMIBr), was investigated as a corrosion inhibitor candidate for mild steel in $1 \mathrm{M} \mathrm{HCl}$ medium using combined electrochemical and molecular simulation methods. Potentiodynamic polarization results show that $\mathrm{HMIBr}$ is a mixed-type inhibitor and suppresses the corrosion process effectively at optimum concentration $10^{-3} \mathrm{M}$ with $96.9 \%$ inhibition efficiency. Electrochemical impedance spectroscopy (EIS) analysis indicated an increase in the charge transfer resistance with enhance of inhibitor concentration, and confirmed the adsorption of HMIBr on the iron surface. Moreover, density functional theory (DFT) calculations, Monte Carlo as well as molecular dynamics simulations were employed to obtain further insights into the antiseptic mechanism. Our findings have important guiding significance for understanding the corrosion inhibition mechanism and designing new ionic liquid-based inhibitor molecules.
\end{abstract}

Keywords: Ionic liquid, Mild steel, Corrosion inhibitor, Electrochemical; Molecular simulation

\section{$\underline{\text { FULL TEXT }}$}

(C) 2020 The Authors. Published by ESG (www.electrochemsci.org). This article is an open access article distributed under the terms and conditions of the Creative Commons Attribution license (http://creativecommons.org/licenses/by/4.0/). 